\title{
Optimization of a Shared Tailrace Channel of Two Pumped-Storage Plants by Physical and Numerical Modeling
}

\author{
Giovanni De Cesare, Martin Bieri, Stéphane Terrier, \\ Sylvain Candolfi, Martin Wickenhäuser and Gaël Micoulet
}

\begin{abstract}
Pump and turbine operations lead to head losses in the tailrace channel. Pumping discharge may be limited due to potential air entrainment into the pump shaft when the downstream reservoir is at its lowest level and the head losses are too high. Regarding turbine operations, the limit is given by the maximum level in the Pelton turbine chamber due to high water level in the downstream reservoir and head losses. The rapid starting and stopping of turbines and pumps lead to highly unsteady flow in the tailrace channel system of the two connected hydropower plants. Negative and positive surges may lead to similar consequences as for stationary operations such as sudden air entrainment into the pump shaft and submerging of the Pelton runner under operation. Therefore, flow and head losses test were conducted on a physical model at 1:30 scale together with numerical
\end{abstract}

\section{G. De Cesare $(\bowtie) \cdot$ S. Terrier}

Laboratoire de Constructions Hydrauliques (LCH), Ecole Polytechnique Fédérale de Lausanne (EPFL), Station 18 CH-1015 Lausanne, Switzerland

e-mail: giovanni.decesare@epfl.ch

S. Terrier

e-mail: stephane.terrier@epfl.ch

S. Candolfi

Université Laval, Québec G1V 0A6, Canada

e-mail: sylvain.candolfi.1@ulaval.ca

M. Wickenhäuser

Stucky Ltd, Rue du Lac 33 CH-1020 Renens, Switzerland

e-mail: mwickenhaeuser@stucky.ch

G. Micoulet

Alpiq Suisse SA, Ch. de Mornex 10, CP 570 CH-1001 Lausanne, Switzerland

e-mail: gael.micoulet@alpiq.com

M. Bieri

Pöyry Energy Ltd, Hardturmstrasse 161 CH-8037 Zürich, Switzerland

e-mail: martin.bieri@a3.epfl.ch; martin.bieri@poyry.com 
simulations using FLOW-3D. On-site measurement of the existing power plant allows validating the results. Representative and extreme operational scenarios have been simulated; the main results are discussed and presented.

Keywords Hydropower $\cdot$ Pumped-storage $\cdot$ Surge waves $\cdot$ Transient flow $\cdot$ Head losses · Free-surface flow • Intake/outlet structure

\section{Introduction}

The existing Hongrin-Léman pumped-storage scheme, located in western Switzerland, commissioned in 1971 and operated by Forces Motrices Hongrin-Léman SA (FMHL), exploits a maximum head of $878 \mathrm{~m}$ between the upper Hongrin reservoir (1'255 $\mathrm{m}$ a.s.1.) and Lake Geneva (372 $\mathrm{m}$ a.s.1.) at the Veytaux 1 underground powerhouse. The powerhouse contains four horizontal axis pumpturbine units with a total installed power of 240 MW. During off-peak periods, water from Lake Geneva is pumped at a maximum rate of $24 \mathrm{~m}^{3} / \mathrm{s}$ to be turbined during periods of high demand with a discharge up to $32 \mathrm{~m}^{3} / \mathrm{s}$. The connection between the powerhouse and Lake Geneva is made by a $200 \mathrm{~m}$ long underground straight free-surface channel. The Hongrin reservoir is formed by a twin-arch dam of 125 and $90 \mathrm{~m}$ height, respectively (Fig. 1). It has an active storage volume of $52 \times 10^{6} \mathrm{~m}^{3}$.

The objective of the FMHL+ enhancement project is to double the today's plant capacity by constructing a new underground cavern adjacent to the existing one at Veytaux (Fig. 1). Two additional vertical axis pump-turbine groups of $120 \mathrm{MW}$ each will be installed. The total power will be $480 \mathrm{MW}$, with $420 \mathrm{MW}$ for operating mode and $60 \mathrm{MW}$ as reserve. The increased flexibility, generating peak electricity, will allow the plant to play an important role in supplying electricity to western Switzerland and to meet the growing demand for balancing energy which is mainly due to the extension new renewable energies in Europe and Switzerland.

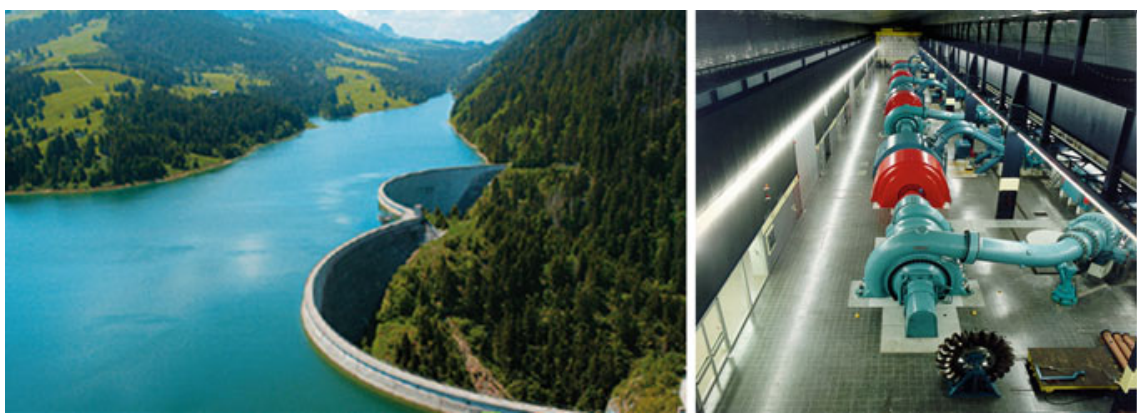

Fig. 1 Hongrin reservoir with the twin-arch dam (left) and view of the existing $170 \mathrm{~m}$ long Veytaux 1 powerhouse (source www.alpiq.ch) 


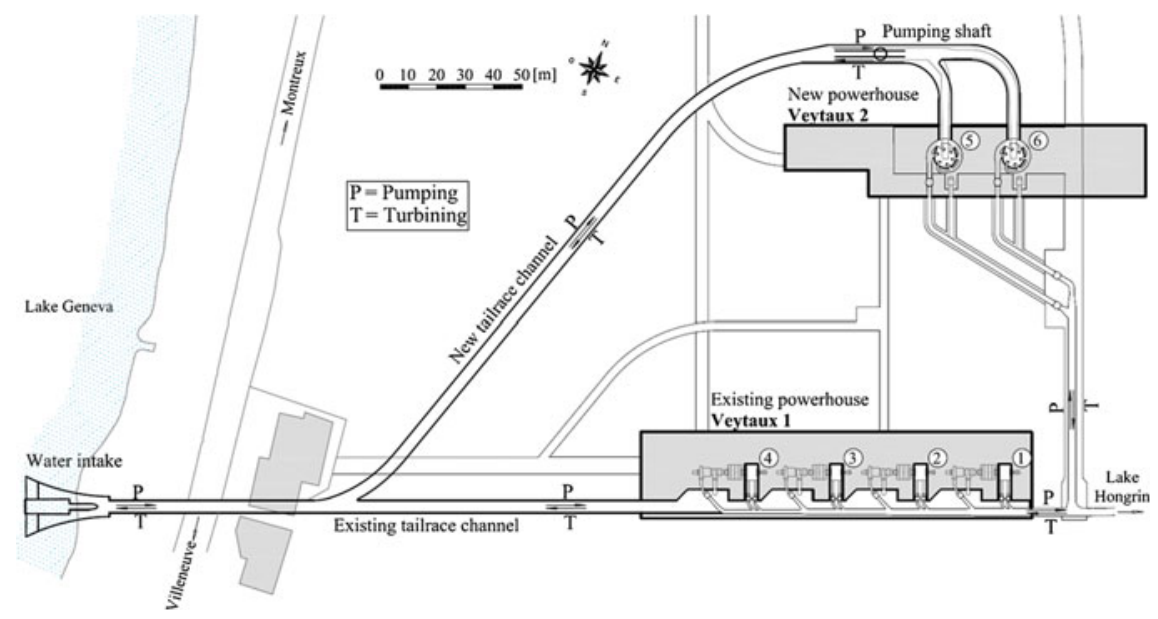

Fig. 2 Plan view of the existing and new Veytaux underground pump-turbine plants

The new plant will mainly use the existing upstream (headrace tunnel and penstock) and downstream (tailrace channel and intake/outlet work) hydraulic system. Figure 2 shows the shared downstream channel system. Special attention has to be paid on the combined operation of the two plants.

This paper presents the results of head loss investigations and wave propagation experiments in the open tailrace channel. The study has been conducted both on a physical model and with numerical 3D simulation. The numerical simulation provided mainly input to the optimization process of the project, before modifying the physical model.

\section{Physical and Numerical Model}

In order to study the unsteady flow behavior, both a physical model and a numerical model were built at the Laboratory of Hydraulic Constructions (LCH) of the Ecole Polytechnique Fédérale de Lausanne (EFPL), Switzerland [1, 2].

\subsection{Physical Model}

The physical model was operated according to Froude similarity with a length-scale ratio of 1:30, replicating the downstream part of the existing Veytaux 1 powerhouse with its $200 \mathrm{~m}$ long tailrace channel to the Lake Geneva as well as the new Veytaux 2 powerhouse with the new $300 \mathrm{~m}$ long tailrace channel connected to the existing one. The two pumps of Veytaux 2 are fed by a single pumping shaft, where only its inlet structure was modeled. All hydraulic elements were built with transparent PVC. Lake Geneva was modeled with a $8 \mathrm{~m}^{3}$ steel tank (Figs. 3, 4). 


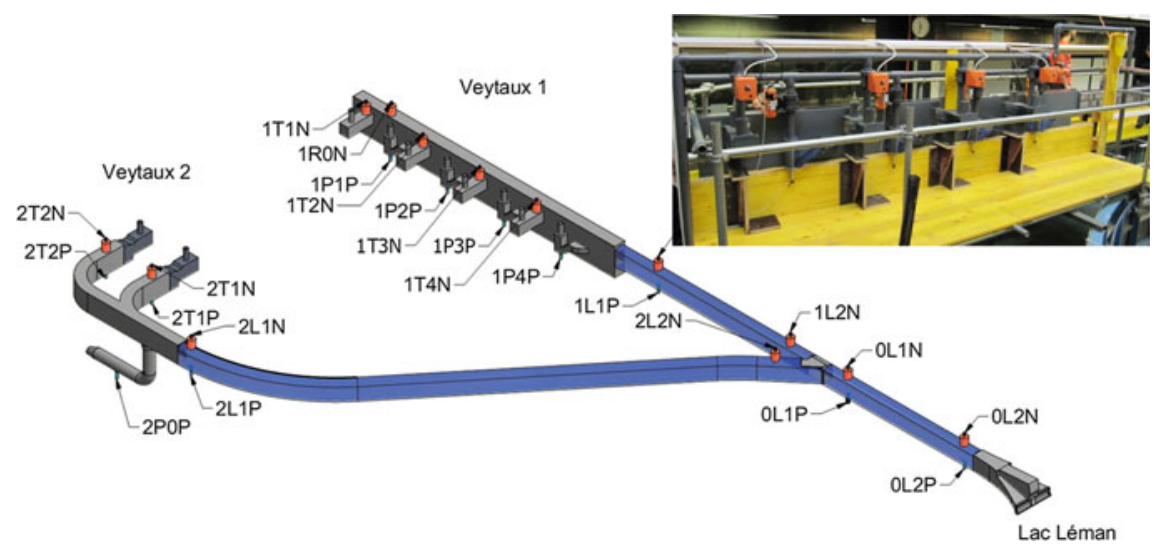

Fig. $33 \mathrm{D}$ view of the physical model showing the positions of water level $(N)$ and pressure $(P)$ sensors for water supply by turbines $(T 1-T 6)$, and sinks by pumps $(P 1-P 6)$ as well as Lake Geneva (Léman) with water intake; photograph of the modeled Veytaux 1 powerhouse with the four turbines and pumps

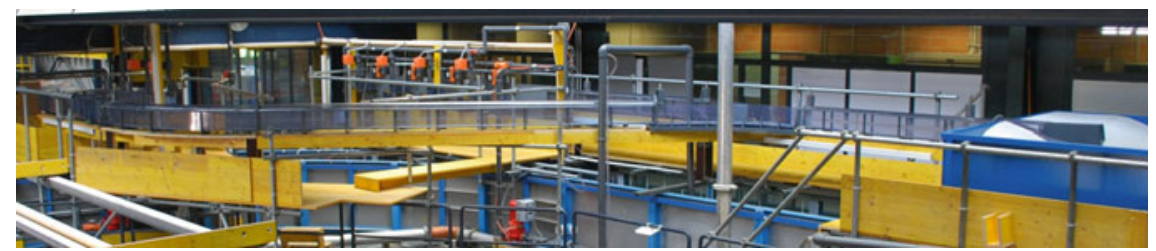

Fig. 4 Overview of the physical model with Lake Geneva tank on the right, Veytaux 1 powerhouse in the background, and Veytaux 2 powerhouse on the far left

\subsection{Numerical Model}

The numerical simulations were carried out using the software FLOW-3D, version 10 from Flow Science Inc. in New Mexico, USA [3]. FLOW-3D numerically solves the continuity and momentum equations using finite-volume approximation. The flow region is subdivided into a mesh of fixed rectangular cells. Within each cell, there are associated local average values of all dependent variables. All variables are located at the center of the cells except for velocities, which are located at cell faces (staggered grid arrangement). Curved obstacles, wall boundaries, or other geometric features are embedded in the mesh by defining the fractional face areas and fractional volumes of the cells that are open to flow (the Fractional Area/Volume Obstacle Representation-FAVOR method). Most terms in the equations are evaluated using the current time-level values of the local 

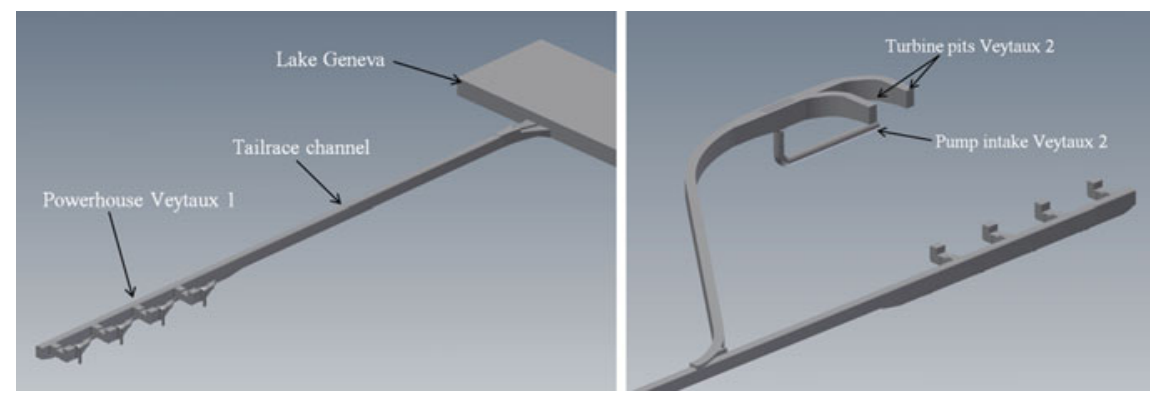

Fig. 5 Numerical FLOW-3D model of the existing Veytaux 1 powerhouse, tailrace channel, and Lake Geneva (left) for the calibration simulation and (right) the added Veytaux 2 branch with the two turbine pits and the pump intakes below

variables explicitly. This produces a simple and efficient computational scheme for most purposes but requires the use of a limited time step size to maintain computationally stable and accurate results. For the simulations, the RNG turbulence model is used, which is similar to the k- $\varepsilon$. The RNG model is better adapted for lower Reynolds numbers as it dynamically evaluates the turbulence length all along the simulation domain (Fig. 5).

The numerical model is built using one mesh block per turbine, respectively, pump unit, the tailrace channel, and Lake Geneva. The splitting into one mesh block per each supply by turbines (T1-T6) and sinks by pumps (P1-P6) is necessary in order to introduce correctly the individual discharges both in steady und unsteady states.

The main calibration parameters of the numerical model are the mesh size, the lake-level boundary condition, and the surface roughness of the concrete tailrace channel. Uniform mesh size of $0.5,1.0$, and $1.5 \mathrm{~m}$ have been tested. The mesh size choice influences largely the duration of the simulation, without any major difference in the obtained results both in space and time for the two smaller ones. Finally, a mesh size of $1 \mathrm{~m}$ has been selected.

As the lake-level boundary condition, a hydrostatic pressure distribution with fixed water level has been selected, giving the most stable results compared to a simple outflow condition, where due to very low flow velocities flow disturbances at the outflow boundary may affect the entire computational domain.

Two $\mathrm{k}_{\mathrm{s}}$ roughness values $(1$ and $2 \mathrm{~cm})$ of the concrete surface in the tailrace channel have been tested based on observation of the real surface irregularities. Their influence is negligible, as the head losses occur as linear head losses for quasi-hydraulically smooth surfaces (due to the very small $\mathrm{k}_{\mathrm{s}}$ over hydraulic radius $\mathrm{R}$ ratio) and as in general, head losses due to surface roughness can be neglected in local head losses due to geometry effects, such as section changes in the water intake. 


\section{Validation Tests}

In a first step, the numerical and physical models were validated for steady-state head losses in pump and turbine mode as well as waves consecutive to the pump or turbine operations in the Veytaux 1 powerhouse. Thanks to on-site measurements taken over several month with an immersed pressure gauge placed in the Veytaux 1 tailrace channel (type Rittmeyer MPB) between the outlets of turbine 1 and 2 (position 1R0 N in Fig. 2), combined with lake-level measurements at an nearby official gauging station and exploitation data over the same period, several typical events have been selected for the validation of the models.

The measurement interval is $10 \mathrm{~s}$ for the $1 \mathrm{R} 0 \mathrm{~N}$ probe, a minimum of $2 \mathrm{~s}$ for the discharge, and $10 \mathrm{~min}$ for the lake gauging station. The accuracy of the on-sitelevel measurements is in the order of $0.2 \%$ of full scale (according to Rittmeyer MPB datasheet), giving some mm exactness. No information is available on the discharge accuracy, but as discharge gradients are of interest, the absolute precision is not so relevant.

The discharge measurements in the physical model (using Endress + Hauser Flowtec Promag $50 \mathrm{~W}$ ) have a precision better than $0.5 \%$ full scale (converted to prototype, less than $0.5 \mathrm{~m}^{3} / \mathrm{s}$ ), the water levels are measured with US gauges (Type Baumer Ultrasonic sensors UNAM 30) with a resolution better than $0.5 \mathrm{~mm}$ (prototype $1.5 \mathrm{~cm}$ ) at an acquisition frequency of $50 \mathrm{~Hz}$.

\subsection{Steady-State Head Losses in Pump and Turbine Mode}

The steady-state validation tests have been conducted with the same prototype boundary conditions as follows:

Lake Geneva water surface elevation: $\quad 372.18-372.22 \mathrm{~m}$ a.s.1.

Discharge of pumping events: $\quad 12.7,20.0$, and $27.1 \mathrm{~m}^{3} / \mathrm{s}$

Discharge of turbining events: $\quad 11.8,19.7,25.1$, and $33.0 \mathrm{~m}^{3} / \mathrm{s}$

Due to exploitation reasons, where only the total energy output (or consumption in pumping mode) of the powerhouse is registered, only the sum of the considered pumping or turbining discharge is known, without the distribution between the four groups of the existing Veytaux 1 powerhouse. This may have a certain impact, as the on-site water level gauge is placed between the outlets of turbine 1 and 2. The different combinations have been tested to see their impact.

Figure 6 gives an overview of the total head losses $\Delta H$ between Lake Geneva and the water level in the powerhouse outlet channel for the considered discharges and water levels from the prototype, physical, and numerical models for both generating and pumping modes. Regarding these results, the physical model seems to be slightly too smooth, underestimating the total head losses. The numerical model, independent of the chosen surface roughness $\mathrm{k}_{\mathrm{s}}$, overestimates slightly the 
Fig. 6 Head losses in function of the discharge between Lake Geneva and the powerhouse outlet channel (1R0N) for the numerical and physical model in both pumping (left) and generating (turbine, right) mode. The approximated minimum and maximum head loss curves are as well positioned
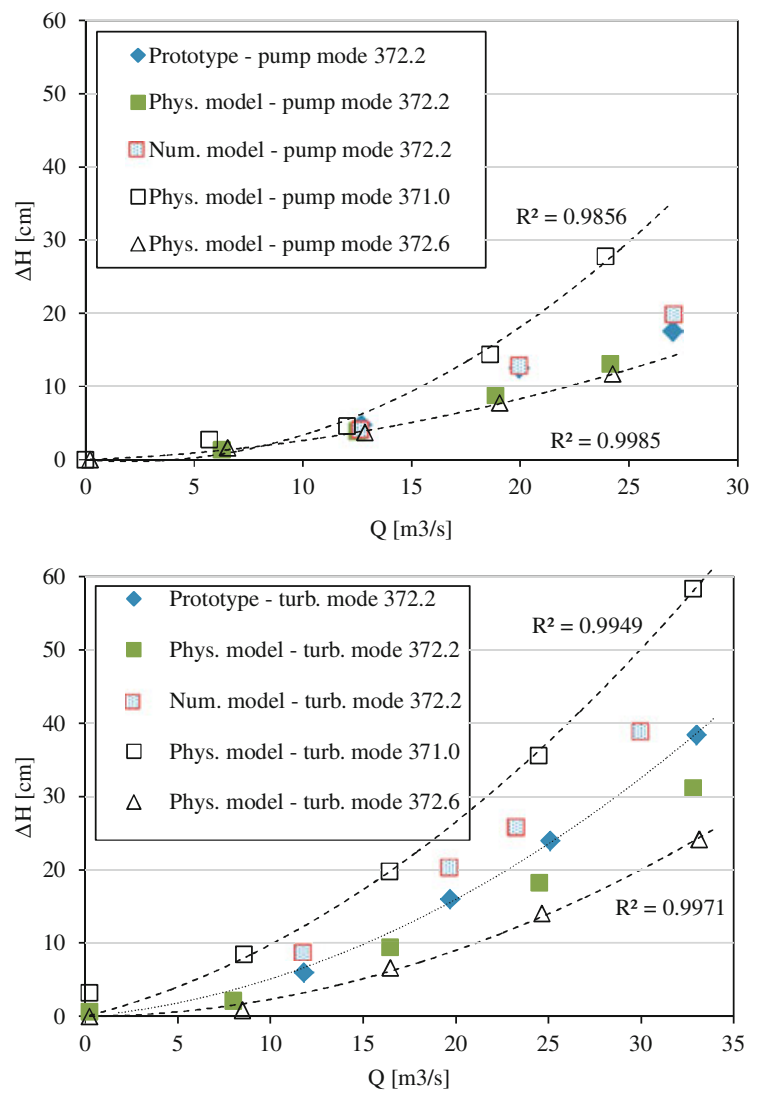

total head losses in turbining mode, but reproducing them trustfully in pumping mode. In conclusion, both approaches give a consistent estimate of the total head losses. For the optimization, mainly the reduction in head losses between two geometrical alternatives is of importance, meaning that both model approaches can be reliably used.

In addition to the validation tests, the physical model has been used to evaluate the minimum and maximum head loss curves taking into account the extreme low and high lake water levels. Both relations follow a parabolic curve (proportional to $\mathrm{Q}^{2}$ ), that is in concordance with the general relations for local and linear head losses.

\subsection{Unsteady Waves Due to Pump and Turbine Start}

The on-site measured start and stop of pumps and turbines in the Veytaux 1 powerhouse have been simulated as well during the validation phase. The numerical simulations were carried out in order to test the mesh size, the 


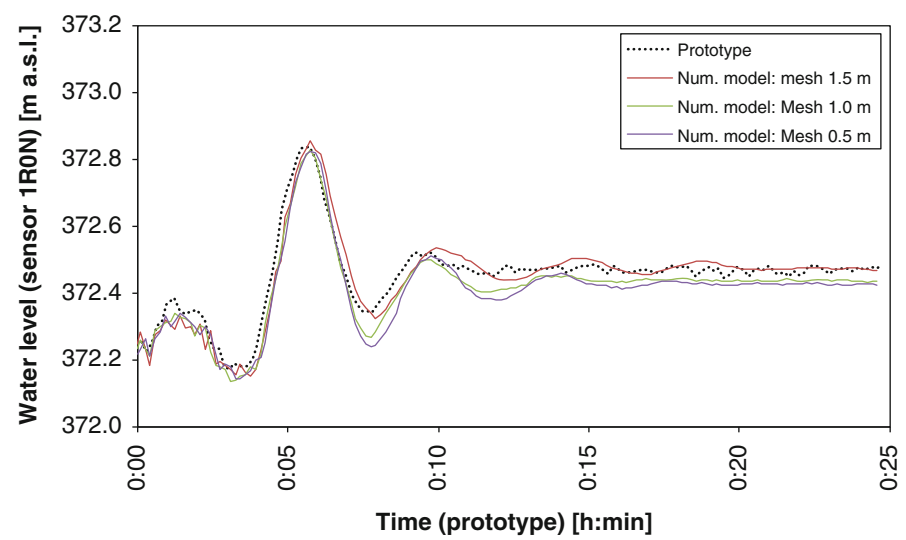

Fig. 7 Start of three turbine groups in the numerical model: influence of the mesh size on the variation of the water level in the Veytaux 1 plant (1R0N), and comparison to prototype measurements. The simulation results show a very good agreement

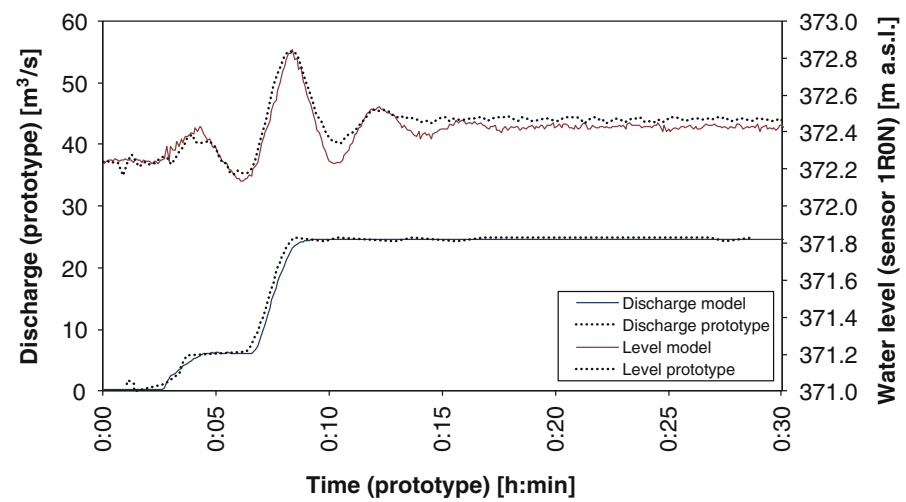

Fig. 8 Results of the physical model test of the same case than for Fig. 6 showing the water level registered at the $1 \mathrm{R} 0 \mathrm{~N}$ probe, located in the Veytaux 1 plant, compared to prototype measurements as well as the discharge variation registered in prototype and physical model. The simulation results show again a very good agreement, and the physical model reproduces identical results to the numerical model

roughness, the turbulence model, the time step size, and the boundary conditions. Figure 7 shows the influence of the start of three turbine groups on the water level fluctuations in the powerhouse outlet channel. The numerical simulation allows a correct representation of the prototype behavior in unsteady stage as well. The rise and fall of the water level and the amplitudes are all well reproduced.

Identical simulations were carried out on the physical model. Figure 8 shows again the influence of the start of three turbine groups on the water level fluctuations in the powerhouse outlet channel, this time from the physical model. The 
discharge changes are overlapped to illustrate the ability of the physical model to reproduce correctly any discharge fluctuations coming from the powerhouse operations, both in turbine and pumping mode. As the exact sequence of turbine start is unknown, all possibilities have been run through, and all showed quasiidentical results from the physical and numerical model.

\section{Simulation Taking into Account Both Powerhouses}

The impact on the head losses as well as on minimum and maximum water levels in the downstream channel, turbine pits, and pump sinks were investigated with a systematic test program. In the physical model, a total of 142 stationary and 85 unsteady tests were conducted, including repetition of typical boundary conditions for the optimized model. The numerical model was mainly used to simulate and optimize the remediation measures on the geometry of particular structures such as the junction, pump sink inlet or outlet/inlet structure into Lake Geneva. Thus, only the final optimized geometry needed to be built and put into the physical model, allowing substantial time and cost savings on the physical model.

\subsection{Steady-State Head Losses in Pump and Turbine Mode and Remedial Measures}

The physical model was used in order to analyze the head losses in the combined operation of the new and old powerhouse for a large range of pumping and turbining discharges as well as lake water levels [4]. The critical conditions are low lake water level with maximum pumping actions as well as high lake water level with maximum turbining discharge. Figure 9 illustrates the case of Lake Geneva's water surface elevation at $371.80 \mathrm{~m}$ a.s.l. for a Veytaux 2 discharge of $24 \mathrm{~m}^{3} / \mathrm{s}$ and Veytaux 1 of $19 \mathrm{~m}^{3} / \mathrm{s}$ using three existing pumps only. Supercritical flow with shock waves occurs from the intake to hydraulic jumps at the bifurcation, leading to large head losses. These head loses lower significantly the water level above the Veytaux 2 pump shaft and entrains air into the shaft. The numerical simulations showed the same behavior and position of the hydraulic jump (Fig. 10).

To remediate the unfavorable head losses, the following four main modifications were proposed. They were at first optimized with the numerical model, then build and installed, and finally tested in the physical model:

1. Partial removal of the central pillar in the intake/outlet structure and reshaping of the remaining pillar like a bridge pier to reduce flow contraction and expansion losses. 


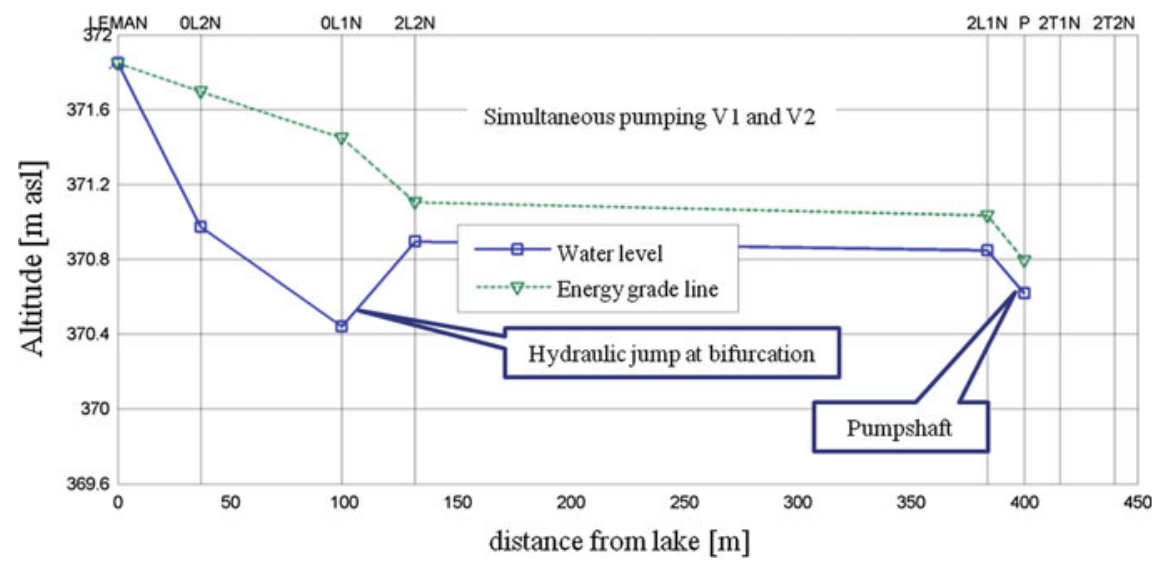

Fig. 9 Head losses and water level lines along the common tailrace channel and Veytaux 2 branch obtained in the physical model. Lake Geneva water surface elevation at $371.80 \mathrm{~m}$ asl for a Veytaux 2 discharge of $24 \mathrm{~m}^{3} / \mathrm{s}$ and Veytaux 1 of $19 \mathrm{~m}^{3} / \mathrm{s}$ using three pumps. The hydraulic jump at the bifurcation is clearly visible, producing undesirable local head losses
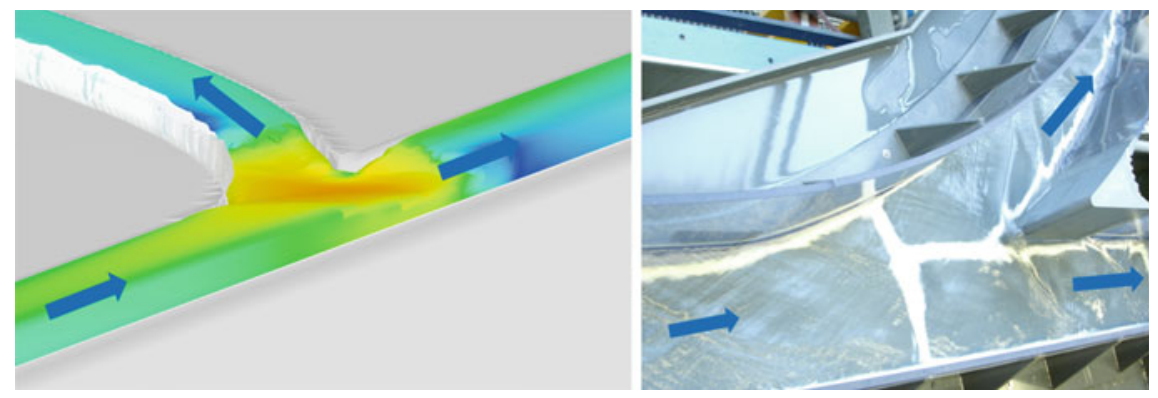

Fig. $103 \mathrm{D}$ hydraulic jump formation at the bifurcation in pumping mode resulting from the numerical simulation (left) and in the physical model (right) for low Lake Geneva water surface elevation at $371.80 \mathrm{~m}$ a.s.l. for Veytaux 2 discharge of $24 \mathrm{~m}^{3} / \mathrm{s}$ and Veytaux $1 \mathrm{of} 19 \mathrm{~m}^{3} / \mathrm{s}$ using three pumps

2. Lowering of the common tailrace channel section by $1 \mathrm{~m}$ to increase wetted flow perimeter and section to prevent supercritical flow and the hydraulic jump at its end. The bottom transitions have a slope of $10 \%$ to join the original levels on both sides.

3. Reshaping of the bifurcation (angle, bottom transition, chamfer of the edge with a series of increasing radii to have an optimum flow separation between the two channels.

4. Reshaping of the Veytaux 2 pump shaft transition (chamfer of the edges, lengthening and widening of the channel, anti-vortex wall prolongation). 
All those modifications, once implemented allowed an accurate functioning of the existing and new powerhouse together for almost any boundary condition. The reshaping of the bifurcation and its results are presented in more details in the section below.

\subsubsection{Reshaping of the Bifurcation}

To reduce the head losses in the bifurcation in pumping mode, two main designs of the junction have been studied (Fig. 11). In the original design, the new tailrace channel is connected laterally to the existing channel with an angle of $35^{\circ}$. The aim of the new design is to soften the change of direction of the flow in the new channel. For that purpose, the new channel makes a turn and is connected tangentially to the existing channel.

For each geometry, numerical simulations in pumping mode were carried out for two levels of Lake Geneva at 371.8 and $371.6 \mathrm{~m}$ a.s.l. and the discharge at Veytaux 2 of $24 \mathrm{~m}^{3} / \mathrm{s}$ and at Veytaux 1 of $19 \mathrm{~m}^{3} / \mathrm{s}$. The corresponding head losses between the common channel and the channels leading to the Veytaux 1 and Veytaux 2 powerhouses are given in Table 1.
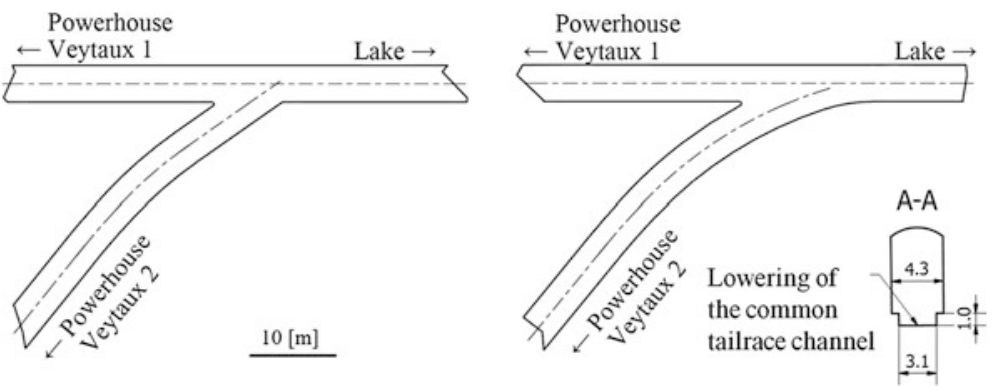

Fig. 11 Plan view of the lateral original bifurcation (left) and the tangential bifurcation (right) with the lowered common channel (bottom)

Table 1 Comparison of the head losses for the lateral and the tangential bifurcation with a level of Lake Geneva at 371.9 and $371.6 \mathrm{~m}$ a.s.l. in pumping mode

\begin{tabular}{llll}
\hline $\begin{array}{l}\text { Level of Lake Geneva } \\
(\mathrm{m} \text { a.s.1.) }\end{array}$ & $\begin{array}{l}\text { Type of } \\
\text { bifurcation }\end{array}$ & $\begin{array}{l}\text { Head losses to Veytaux } \\
1(\mathrm{~cm})\end{array}$ & $\begin{array}{l}\text { Head losses to Veytaux } \\
2(\mathrm{~cm})\end{array}$ \\
\hline 371.8 & $\begin{array}{l}\text { Lateral bifurcation } \\
\text { Tangential }\end{array}$ & 5 & 20 \\
$\quad$ bifurcation & 11 & 3 \\
371.6 & & 68 \\
& $\begin{array}{l}\text { Lateral bifurcation } \\
\text { Tangential }\end{array}$ & 29 & 83 \\
& bifurcation & & \\
\hline
\end{tabular}



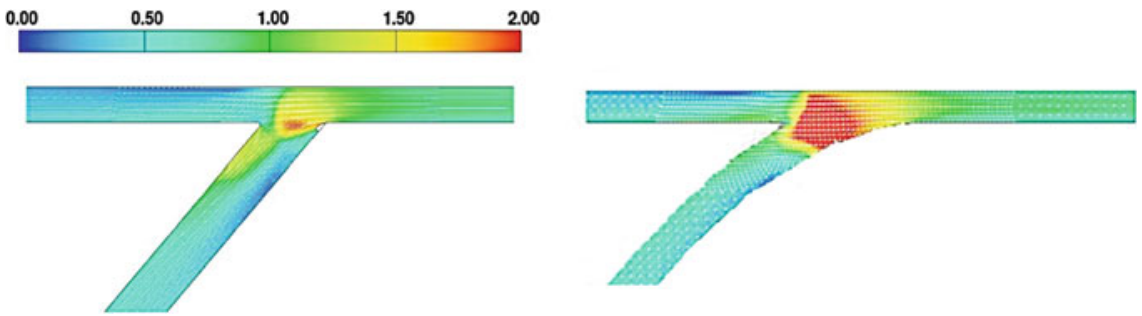

Fig. 12 Froude number in the lateral bifurcation (left) and tangential bifurcation (right) with Lake Geneva at $371.6 \mathrm{~m}$ a.s.1

In the case of the Lake Geneva with a level of $371.8 \mathrm{~m}$ a.s.l., the tangential bifurcation reduces the head losses toward Veytaux 2 powerhouse by a factor of almost 7 but doubles the head losses toward Veytaux 1. The flow is more equally divided between the two channels for the tangential bifurcation; the head losses are more equally distributed.

With a low level of Lake Geneva (371.6 $\mathrm{m}$ a.s.1.), the head losses are increased due to the higher kinetic energy. The head losses are equally divided ( 88 for Veytaux 1 and $83 \mathrm{~cm}$ for Veytaux 2) with the tangential bifurcation. The hydraulic jump is stronger in the case of the tangential bifurcation due to the widening of the channel at the bifurcation (Fig. 12). To counteract this, the bottom of the common channel will be lowered by $1 \mathrm{~m}$ in its central section ( $3.1 \mathrm{~m}$ wide) with a gradual slope at the bifurcation, reducing considerably Froude number and therefore the intensity of the hydraulic jump.

\subsection{Unsteady Waves Due to Pump and Turbine Start}

The main objectives of the unsteady wave tests were to identify critical exploitation scenarios that may endanger the safe operation of both power plants. Due to the complex wave behavior with reflection of the surface waves at each channel end, at the Lake Geneva boundary and at the bifurcation, the physical model was used to conduct these tests $[5,6]$. Typical start and stopping situations of turbines and pumps were simulated, taking into account the most critical sequences as well as the synchronization with the grid.

Figure 13 shows the water level evolution above the Veytaux 2 pump shaft for a typical operation scenario with the start of three pumps of the Veytaux 1 powerhouse and Veytaux 2. It also shows the identification of the most critical combination sequence. The results illustrate that it is not possible to overlap the minimum water level produced by each powerhouse for a combined powerhouse operation, thus reducing restrictions in grid regulation operation. The same 


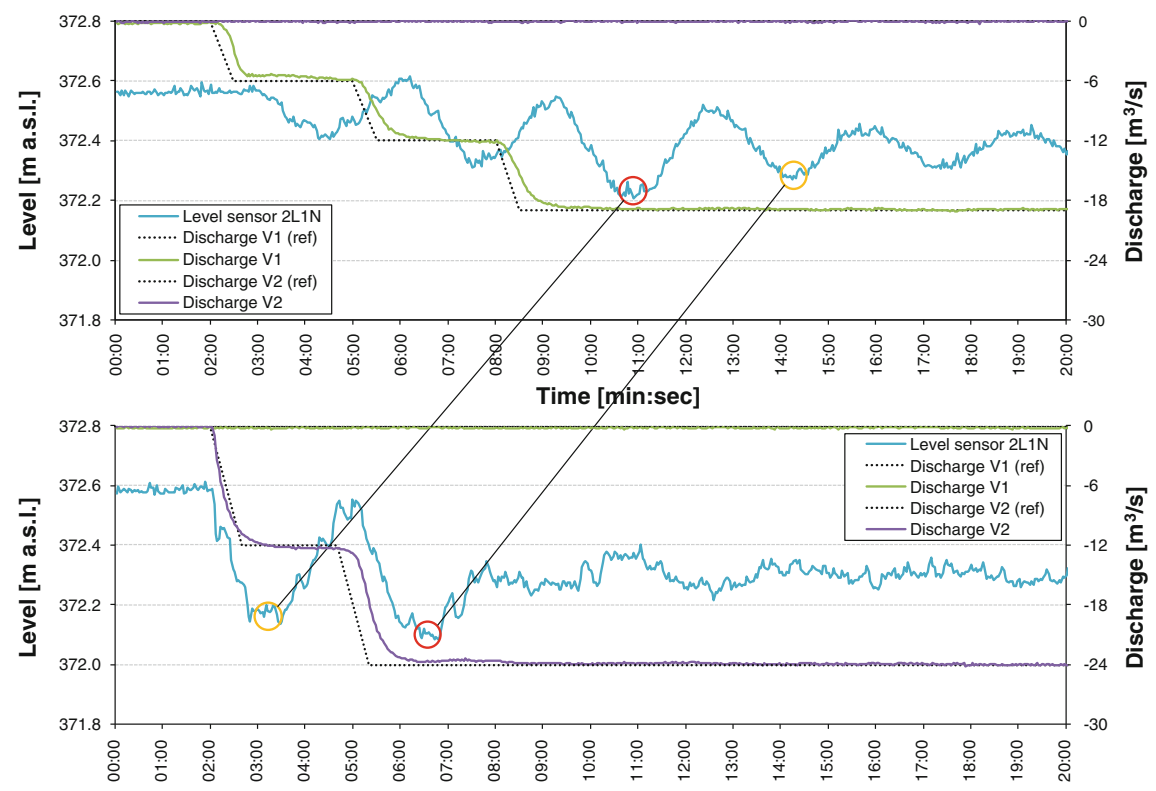

Fig. 13 Local wave evolution in the downstream tailrace channel of the Veytaux 2 plant (probe 2L1N, see Fig. 3) for sequential pump start with three pumps for Veytaux 1 (top) and two pumps for Veytaux 2 (bottom) plants. The minimum water levels cannot be overlaid due to the length of the connection channel

statement is valid for turbine operation, where the surge waves will not rise in the turbine pits to an extend that may endanger their safe operation.

\section{Conclusions}

The existing Hongrin-Léman pumped-storage scheme, $240 \mathrm{MW}$ with four pumpturbine units, is currently under power extension work to double the current plant's capacity by constructing a new powerhouse adjacent to the existing one with two additional vertical axis pump-turbine groups of $120 \mathrm{MW}$ each. Both power plants share the intake and outlet structures and part of the existing tailrace channel at Lake Geneva which is the downstream reservoir. A physical model at a scale of 1:30 and a numerical model at prototype scale were built at the Laboratory of Hydraulic Constructions of the Ecole Polytechnique Fédérale de Lausanne with the aim of studying the future stationary and transient behavior of the two plants. Stationary pump and turbine operations lead to head losses in the tailrace channel that have to be minimized to allow the envisaged flexible operation. Power generation or storage by pumping as well as grid stabilization and frequency 
regulation leads to highly transient bidirectional flows in the tailrace channel system that have to be understood.

At the beginning, the numerical and physical models were validated for steadystate head losses in pump and turbine mode as well as for waves consecutive to the pump or turbine start in the existing powerhouse. Both approaches give consistent values for the head losses in the tailrace channel as well as for level variation in the powerhouse. Both model approaches can be reliably used for the optimization of geometrical elements to reduce local head losses. Thanks to its fast and simple geometrical adaption, the numerical model has mainly been used to optimize the geometry before constructing and implementing the modified elements in the physical model. The final goal of having a tailrace channel giving satisfactory low head losses was achieved and tested in the physical model after several required modifications.

In order to understand the negative and positive surge waves due to characteristic start and stopping situations of turbines and pumps, some 85 unsteady tests were conducted. The tests confirmed that envisaged flexible operation scenarios should not lead to negative consequences such as vortices and air entrainment into the pump shaft and submersion of the turbine pits under operation. The physical and numerical models allowed optimizing and rendering of the downstream hydraulic system viable. The enhanced scheme was tested in detail in order to analyze critical stationary and transient scenarios and to define the operation limits of two power plants together.

Physical modeling and experimental research is more than 100 years old and is a proven tool for hydraulic engineering. Most of today's created or transformed dams, hydroelectric, or flood control projects pass over one or more phases of physical modeling in their specification phase. These models are more and more endorsed by numerical simulations, giving another very powerful, complementary tool for an insight view on hydraulics and hydraulic works [7].

Acknowledgments This study has been conducted on behalf of the plant owner FMHL. We address our gratitude having retained the LCH for this model study and for allowing the LCH to exploit the model for scientific research. A part of the numerical study has been conducted during an alternative civilian service.

\section{References}

1. LCH (2011). Augmentation de la puissance de l'aménagement Hongrin-Léman-Essais sur modèle numérique 3D. LCH Report (unpublished) 06/2011, EPFL Lausanne (in French).

2. LCH (2012). Augmentation de la puissance de l'aménagement Hongrin-Léman-Etude sur modèle physique. LCH Report (unpublished) 03/2012, EPFL Lausanne (in French).

3. Flow Science (2011). Flow-3D user manual, Flow Science Inc., Santa Fe, USA

4. Blevins, R. D. (1984). Applied fluid dynamics handbook (p. 558). New York: Van Nostrand Reinhold Co.

5. Faure, J., \& Nahas, N. (1961). Etude numérique et expérimental d'intumescences à forte courbure du front. Intumescences—Société hydrotechnique de France, 5, 579-587. 
6. Soares-Frazao, S., \& Zech, Y. (2002). Undular bores and secondary waves-Experiments and hybrid finite-volume modelling. Journal of Hydraulic Research, 40(1), 33-43.

7. De Cesare, G., Pfister, M., Daneshvari, M. Bieri, M. (2012). Herausforderungen des heutigen wasserbaulichen Versuchswesens mit drei Beispielen. WasserWirtschaft, 7-8, ISSN: 0043-0978 (in German). 